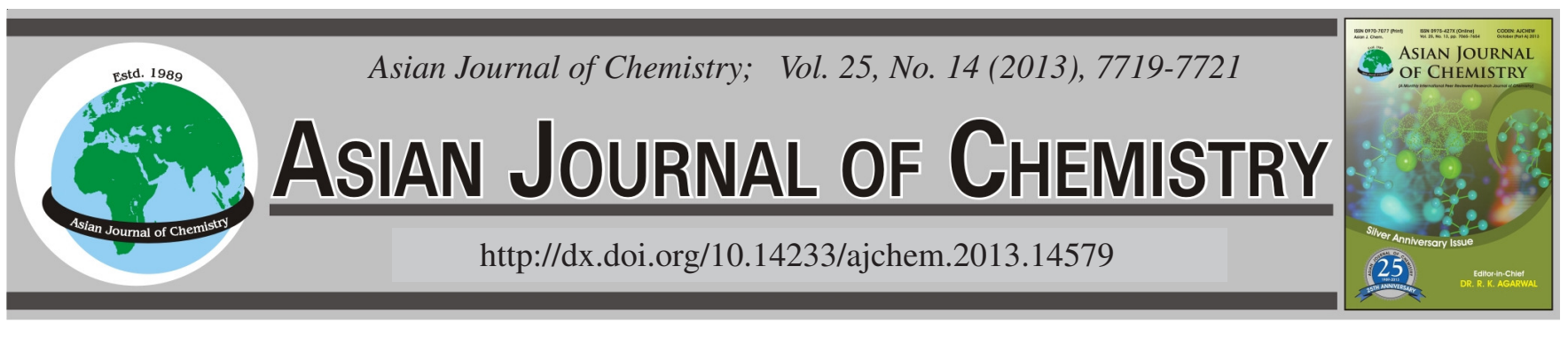

\title{
Larvicidal Carbazole Alkaloids from Murraya koenigii Against Dengue Fever Mosquito Aedes aegypti Linnaeus
}

\author{
M.A. Sukari ${ }^{1,}$, H.S. Mohd Noor ${ }^{1}$, N.H. Abu BaKar ${ }^{1}$, G.C.L. Ee ${ }^{1}$, I.S. Ismail ${ }^{1}$, M. RAhmani ${ }^{1}$ and A.B. Abdul ${ }^{2}$
}

${ }^{1}$ Department of Chemistry, Faculty of Science, Universiti Putra Malaysia, 43400 UPM Serdang, Selangor, Malaysia

${ }^{2}$ UPM-MAKNA Cancer Research Laboratory, Institute of Bioscience, Universiti Putra Malaysia, 43400 UPM Serdang, Selangor, Malaysia

*Corresponding author: E-mail: aspollah@science.upm.edu.my

(Received: 15 September 2012;

Accepted: 11 July 2013)

AJC-13793

\begin{abstract}
Phytochemical studies on different parts of Murraya koenigii (L.) have resulted in the isolation of six carbazole alkaloids which have been identified as mahanimbine (1), girinimbine (2), murrayacine (3), murrayanine (4), murrayafoline-A (5) and 3-methylcarbazole (6) together with $\beta$-sitosterol. The structures of these compounds were established using spectroscopic techniques. The crude extracts and chemical constituents obtained from the isolation work were tested on its larvicidal activity against dengue fever mosquito, Aedes aegypti. Hexane extract from stem bark, roots and leaves of Murraya koenigii showed strong activity against Aedes aegypti followed by chloroform extract of the roots and leaves. Methanol extract of the leaves also showed strong activity while methanol extract of the roots showed moderate activity. Besides, chloroform and methanol extracts from stem bark showed strong activity. Similarly, pure compounds isolated from the plant, mahanimbine (1), girinimbine (2), murrayacine (3), murrayanine (4) and murrayafoline A (5) exhibited strong activity against Aedes aegypti with $\mathrm{LC}_{50}$ values of less than $3 \mu \mathrm{g} / \mathrm{mL}$.
\end{abstract}

Key Words: Murraya koenigii, Carbazole alkaloid, Larvicidal activity, Aedes aegypti.

\section{INTRODUCTION}

Mosquito are divided into two groups, Culex and Aedes, but perhaps the more important group is genus Aedes. Dengue and yellow fever are transmitted by Aedes aegypti which also known as yellow fever mosquito. According to the World Health Organization ${ }^{1}$, the virus of the dengue fever is the most important arbovirus to man in the world and since Aedes has been found to transmit this virus, it has been widely studied and blamed as the vector. Dengue fever was first reported in Malaysia in 1902 and is now one of the major public health problems in Malaysia, especially with the emergence of dengue haemorrhagic fever in 1962. Notification of dengue fever and dengue haemorrhagic fever was instituted in 1971, requiring all medicine practitioners to report any case of conformed or suspected dengue or dengue haemorrhagic fever to the nearest health office. Prevention and control of dengue fever and dengue haemorrhagic fever was further strengthened with the enactment of the destruction of disease bearing insect act 1975 which has amended in 2001 with heavier penalties.

Plant derived products have received increased attention from scientists and more than 2000 plant species are already known to have insecticidal properties. Plant extracts and isolated compounds are considered to be a potential alternative approach against various stages and species of mosquitoes due to their excellent properties like environment safety nature. Besides, the bioactive ingredients of the plants can also act as ovicidal, repellent, oviposition, deterrence, reduction of recundity and fertility, larvicidal and also insect grown regulator ${ }^{2}$. One of the available methods used for the control of mosquitoes is by using chemical insecticides. The method is favourable because of their fast action and easy application. However, their repeated and excessive uses have developed the resistance among the insects and posses severe health hazards and environmental problems ${ }^{3}$.

Murraya koenigii belongs to the family of Rutaceae, commonly known as curry-leaf tree. It is an aromatic plant that has long been used as folk medicines in Asian countries. Murraya koenigii normally used as natural flavoring in curries and souces ${ }^{4}$ and commonly found in India and Peninsula Asia. Murraya koenigii is known as one of the richest source of carbazole alkaloids ${ }^{5}$. It has been reported that carbazole alkaloid posses various biological activities such as antitumour, antioxidative, antimutagenic and antiinflammatory activities ${ }^{6,7}$. Part of the plant has been used as raw material for the traditional medicine formulation in India. The leaves stem bark and roots of Murraya koenigii can be used as a tonic and a stomachic. The bark and the roots are used as a stimulant by the physicians. 
They are also used externally to cure eruption and the bite of poisonous animals. Other than use as indigenous medicine, Murraya koenigii possess insecticidal properties as antifeedant. In continuation of our investigation on Rutaceae plants, phytochemical and bioactivity studies on $M$. koenigii were carried out. Our previous works on roots and stem bark of the plant have led to the isolation of carbazole alkaloids ${ }^{8}$. This present study was carried out to evaluate the larvicidal activities on constituents of Murraya koenigii against the vector mosquitoes of Aedes aegypti.

\section{EXPERIMENTAL}

M. koenigii used in this study was collected from Sik, Kedah in December 2005. The plant material was ground and air-dried prior being used. Melting points (uncorrected) were determined on Kohfler melting points apparatus. The IR spectra were recorded using $\mathrm{KBr}$ disc on Perkin Elmer FTIR spectrophotometer model $1725 \mathrm{X} .{ }^{1} \mathrm{H}$ and ${ }^{13} \mathrm{C}$ NMR spectra were obtained on JOEL Spectrometer at 400 and $100 \mathrm{MHz}$, respectively with tetramethylsilane as internal standard. Mass spectra were recorded on Shimadzu model QP5050A at 70 eV. Column chromatography was carried using silica gel (Merck 7749) and Merck silica gel $60 \mathrm{PF}_{254}$ was used for thin layer chromatography analysis.

Extraction and isolation of compounds: The finely ground stem bark of $M$. koenigii $(0.5 \mathrm{~kg})$ was extracted successively with hexane, chloroform and methanol three times each to give $22.5,10.0$ and $10.1 \mathrm{~g}$ of crude extracts, respectively. The crude extracts were subjected to column chromatography separations using mixtures of hexane, ethyl acetate and methanol with increasing polarities as eluting solvents. The hexane extract (19.5 g) yielded mahanimbine (1) (4.22 g) and girinimbine (2) (0.35 g). Similarly, dried roots of $M$. koenigii $(0.5 \mathrm{~kg})$ were extracted with hexane, chloroform and methanol to give 33.0, 14.0 and $29.8 \mathrm{~g}$ of crude extracts, respectively while the leaves of $M$. koenigii $(0.5 \mathrm{~kg})$ gave hexane, chloroform and methanol extracts of 33.5, 43.0 and $40.0 \mathrm{~g}$, respectively. Work-up procedure on hexane crude extract of roots of $M$. koenigii afforded mahanimbine (1) $(0.23$ $\mathrm{g})$, girinimbine (2) (0.64 g), murrayacine (3) (0.51 g), murrayafoline-A (5) (0.95 g) and $\beta$-sitosterol (30 mg), while chloroform crude extracts (14.0 g) gave girinimbine (2) (0.17 g), murrayanine (4) (0.59 g), murrayafoline A (5) (0.21 g) and 3-methylcarbazole (6) $(10 \mathrm{mg})$.

Mahanimbine (1): White solid, $\mathrm{C}_{23} \mathrm{H}_{25} \mathrm{NO}$, m.p. 88-90 ${ }^{\circ} \mathrm{C}$ (lit. ${ }^{9}$, m.p. $\left.94-95^{\circ} \mathrm{C}\right)$. IR (KBr, $\left.v_{\max }, \mathrm{cm}^{-1}\right): 3324,2924,1646$, $1610,1458,1378,1218,1156,1084 . \mathrm{MS}(\mathrm{m} / \mathrm{z}, \%$ intensity): $m / z 331\left(\mathrm{M}^{+}, 17\right), 316(4), 248$ (100), 218 (5), 204 (8), 69 (4), 55 (4). ${ }^{1} \mathrm{H}$ and ${ }^{13} \mathrm{C}$ NMR data were described in previous report ${ }^{8}$.

Girinimbine (2): White crystals, $\mathrm{C}_{18} \mathrm{H}_{17} \mathrm{NO}$, m.p. 175$177{ }^{\circ} \mathrm{C}$ (lit. ${ }^{9}$, m.p. $\left.177-178{ }^{\circ} \mathrm{C}\right)$. IR ( $\left.\mathrm{KBr}, \mathrm{v}_{\max }, \mathrm{cm}^{-1}\right)$ : 3316 , 3064, 2974, 2930, 1742, 1640, 1606, 1458, 1360, 1206, 1022. MS ( $m / z, \%$ intensity): $m / z 263\left(\mathbf{M}^{+}, 69\right), 248$ (100), 231 (8), 218 (10), 204 (17), 191 (5), 131 (5), 124 (66), 102 (16), 95 (6). ${ }^{1} \mathrm{H}$ and ${ }^{13} \mathrm{C}$ NMR data were described in previous report ${ }^{8}$.

Murrayacine (3): Greenish crystal, $\mathrm{C}_{18} \mathrm{H}_{15} \mathrm{NO}_{2}$, m.p. 207$209^{\circ} \mathrm{C}$ (lit. ${ }^{9}$, m.p. $\left.205-208^{\circ} \mathrm{C}\right) \mathrm{IR}\left(\mathrm{KBr}, \mathrm{v}_{\max }, \mathrm{cm}^{-1}\right)$ : 3432, 1662 , 1636, 1606, 1580, 1498, 1454, 1342, 1314, 1200, 1162. MS ( $\mathrm{m} / \mathrm{z}, \%$ intensity): $\mathrm{m} / \mathrm{z} 277\left(\mathbf{M}^{+}, 39\right), 262$ (100), 248 (5), 234
(12), 204 (12), 131 (25), 102 (11). ${ }^{1} \mathrm{H}$ and ${ }^{13} \mathrm{C}$ NMR data were described in previous report ${ }^{8}$.

Murrayanine (4): White needle-shaped crystals, $\mathrm{C}_{14} \mathrm{H}_{11} \mathrm{NO}_{2}$, m.p. $165-167^{\circ} \mathrm{C}$ (lit. ${ }^{9}$, m.p. $168-169^{\circ} \mathrm{C}$ ). IR (KBr, $\left.v_{\max }, \mathrm{cm}^{-1}\right): 3150,1662,1608,1578,1450,1342,1240,1138$. MS ( $m / z, \%$ intensity): $m / z 225\left(\mathbf{M}^{+}, 100\right), 210$ (67), 196 (7), 182 (22), 181 (11), 154 (61), 153 (21), 126 (28), 112 (7), 98 (14), 87 (10), 63 (8), 51 (21). ${ }^{1} \mathrm{H}$ and ${ }^{13} \mathrm{C}$ NMR data were described in previous report ${ }^{8}$.

Murrayafoline A (5): Yellowish needle-shaped crystal, $\mathrm{C}_{14} \mathrm{H}_{13} \mathrm{NO}$, m.p. $50-52{ }^{\circ} \mathrm{C}$ (lit. ${ }^{9}$, low melting point). IR (KBr, $\left.V_{\max }, \mathrm{cm}^{-1}\right): 3546,3448,2996,1694,1590,1450,1388,1254$, 1034, 1016. MS (m/z, \% intensity): $\mathrm{m} / \mathrm{z} 221\left(\mathbf{M}^{+}, 100\right), 196$ (73), 182 (3), 168 (43), 167 (36), 139 (5), 106 (9), 84 (6). ${ }^{1} \mathrm{H}$ and ${ }^{13} \mathrm{C}$ NMR data were described in previous report ${ }^{8}$.

3-Methylcarbazole (6): White powder, $\mathrm{C}_{13} \mathrm{H}_{11} \mathrm{~N}$, m.p. 198 to $200{ }^{\circ} \mathrm{C}$ (lit. ${ }^{9}$, m.p. $205-208{ }^{\circ} \mathrm{C}$ ) IR $\left(\mathrm{KBr}, v_{\max }, \mathrm{cm}^{-1}\right): 3406$, 3050, 2856, 2376, 1628, 1640, 1334, 1242, 1172, 1030. MS (m/z, \% intensity): $\mathrm{m} / \mathrm{z}, 181\left(\mathrm{M}^{+}, 100\right), 154(5), 152(14), 127$ (3), 90 (38), 77 (16), 63 (7).

Determination of larvicidal activity test: Larvicidal activity tests were carried out on the crude hexane, chloroform, methanol extracts from roots, stem bark and leaves of Murraya koenigii against mosquito larvae of Aedes aegypti. Standard methods for assaying larvicidal activity as recommended by the world health organization (WHO) were followed in all experiments (WHO/VBC/81.807) with some modifications. Preliminary bioassays were performed with third instar larvae of Aedes aegypti and were carried out in duplicate using 10 larvae for each replicate assay. The larvae were placed into $250 \mathrm{~mL}$ drinking glasses containing $25 \mathrm{~mL}$ of chlorine-free water introduced with stock solution and maintained at $27^{\circ} \mathrm{C}$. Then the volume was filled up to $50 \mathrm{~mL}$ with chlorine-free water. Larvae food (ground roasted chicken's liver) was added. Larvae were considered dead when they were unable to reach the surface of the solution while the glasses are shaken. The number of dead larvae was estimated while the experiment started within 24 and $48 \mathrm{~h}$. An aqueous solution of absolute ethanol was determined as the negative control while acetone served as the positive control. Treatments that showed at least $50 \%$ mortality within $48 \mathrm{~h}$ were followed-up by further bioassays of the same sample at different concentrations in order to determine the concentration required to kill $50 \%\left(\mathrm{LC}_{50}\right)$ of the larvae present. The analysis of the follow-up assays was carried out according to the probit analysis method ${ }^{1}$. The larvicidal activity of the isolated compounds (1)-(6) against larvae of Aedes aegypti were carried out using the same procedures.

\section{RESULTS AND DISCUSSION}

Stem bark, roots and leaves of Murraya koenigii were extracted successively with hexane, chloroform and methanol. The fractionation of these crude extracts followed by column chromatography separation yielded six carbazole alkaloids which were identified as mahanimbine (1), girinimbine (2), murrayacine (3) murrayanine (4), murrayafoline-A (5) and 3methylcarbazole (6) (Fig. 1) together with $\beta$-sitosterol. The details on the isolation and characterization of carbazole alkaloids have been described previously ${ }^{8}$. 
<smiles>[R]c1ccc2c3cc([R2])c4c(c3n([2H])c2c1)CCC([R])(C)O4</smiles><smiles>[2H]c1cc(Br)cc2c1[nH]c1ccccc12</smiles>

(1) Mahanimbine: $\mathrm{R}_{1}=\mathrm{H}, \mathrm{R}_{2}=\mathrm{CH}_{3}, \mathrm{R}_{3}=-\left(\mathrm{CH}_{2}\right)_{2} \mathrm{CH}=\mathrm{C}\left(\mathrm{CH}_{3}\right)_{2}$

(2) Girinimbine: $\mathrm{R}_{1}=\mathrm{H}, \mathrm{R}_{2}=\mathrm{R}_{3}=\mathrm{CH}_{3}$; (3): Murrayacine : $\mathrm{R}_{1}=\mathrm{H}, \mathrm{R}_{2}=$ $\mathrm{CHO}, \mathrm{R}_{3}=\mathrm{CH}_{3}$; (4) Murrayanine: $\mathrm{R}_{1}=\mathrm{CHO}, \mathrm{R}_{2}=\mathrm{OCH}_{3}$; (5) Murrayafoline A: $\mathrm{R}_{1}=\mathrm{CH}_{3}, \mathrm{R}_{2}=\mathrm{OCH}_{3}$; (6) 3-Methylcarbazole: $\mathrm{R}_{1}=\mathrm{CH}_{3}, \mathrm{R}_{2}=\mathrm{H}$

Fig. 1. Structures of the larvicidal compounds

Plants belonging to the Rutaceae family which are rich sources of bioactive organic chemicals have potential to be used as botanical pesticides for eradication of mosquito larvae. The bioactivity of constituents of plant extracts against mosquito larvae are influenced by the plant species, solvents of extraction and mosquito species used in the assay. Plant sample of Murraya koenigii was extracted using various solvents and tested for larvicidal activity against mosquito larvae of A. aegypti. The larvicidal bioassay was carried out according method recommended by $\mathrm{WHO}^{1}$, with slight modifications. Nine crude extracts from roots, stem barks and leaves of $M$. koenigii as well as isolated carbazole alkaloids were tested for their larvicidal activity against larvae of dengue fever mosquito Aedes aegypti.

Table- 1 shows the result on $\mathrm{LC}_{50}$ values of various extracts of the roots, stem bark and leaves of $M$. koenigii. Hexane extracts of roots, stem bark and leaves showed very strong activity with $\mathrm{LC}_{50}$ of $1.75,4.46$ and $1.88 \mu \mathrm{g} / \mathrm{mL}$, respectively. This is followed by chloroform extracts of roots and leaves which also showed very strong activity with $\mathrm{LC}_{50}$ values of 4.33 and $2.69 \mu \mathrm{g} / \mathrm{mL}$, respectively. In addition, chloroform and methanol extracts from stem bark showed strong activity with $\mathrm{LC}_{50}$ values of 16.32 and $24.03 \mu \mathrm{g} / \mathrm{mL}$, respectively. Besides, methanol extract of leaves of Murraya koenigii also gave noticeably very strong activity against $A$. aegypti with $\mathrm{LC}_{50} 9.89 \mu \mathrm{g} / \mathrm{mL}$. However, the methanol extract of the roots showed moderate activity with $\mathrm{LC}_{50}$ of $58.46 \mu \mathrm{g} / \mathrm{mL}$. Table-2 shows the larvicidal activity of pure compounds isolated from Murraya koenigii against mosquito larvae of Aedes aegypti. All the pure compounds tested; mahanimbine (1), girinimbine (2), murrayacine (3), murrayanine (4) and murrayafoline A (5) showed very strong activity against Aedes ageypti with $\mathrm{LC}_{50}$ values of $0.68,0.79,2.51,1.14$ and $0.43 \mu \mathrm{g} / \mathrm{mL}$, respectively. The significant larvicidal activitiy of the crude extracts were undoubtfully been contributed by synergistic effect of these bioactive carbazole alkaloids. The larvicidal activity of crude plant extracts of Murraya koenigii and isolated carbazole alkaloids against larvae of Aedes aegypti have never been reported previously. Thus, the crude extracts especially nonpolar extracts of M. koenigii can be potential source of natural mosquito larvicides against larvae of Aedes aegypti. The larvicidal activity of the plant isolates are comparable to well known botanical insecticides, Azadirachta indica (Table-1). More detail study on the larvicidal assessment of extracts of Murraya koenigii together with the isolated carbazole alkaloids warrant further investigation.
TABLE-1

LARVICIDAL ACTIVITY OF CRUDE EXTRACTS FROM Murraya koenigii AGAINST MOSQUITO LARVAE OF Aedes agypti

\begin{tabular}{lccc}
\hline Part of plant & Extracts & $\mathrm{LC}_{50}(\mu \mathrm{g} / \mathrm{mL}) *$ & Slope \pm S.E** \\
\hline Roots & $\mathrm{C}_{6} \mathrm{H}_{12}$ & 1.75 & $1.97 \pm 0.27$ \\
& $\mathrm{CHCI}_{3}$ & 4.33 & $1.82 \pm 0.25$ \\
& $\mathrm{CH}_{3} \mathrm{OH}$ & 58.46 & $2.42 \pm 0.62$ \\
\hline Stem barks & $\mathrm{C}_{6} \mathrm{H}_{12}$ & 4.46 & $1.98 \pm 0.29$ \\
& $\mathrm{CHCI}_{3}$ & 16.32 & $1.80 \pm 0.24$ \\
& $\mathrm{CH}_{3} \mathrm{OH}$ & 24.03 & $1.62 \pm 0.22$ \\
\hline Leaves & $\mathrm{C}_{6} \mathrm{H}_{12}$ & 1.88 & $1.10 \pm 0.15$ \\
& $\mathrm{CHCI}_{3}$ & 2.69 & $1.11 \pm 0.16$ \\
& $\mathrm{CH}_{3} \mathrm{OH}$ & 9.89 & $0.76 \pm 0.13$ \\
\hline Azadirachta indica & - & $1.2-18.0$ & N.A \\
\hline \multicolumn{2}{l}{$<$ 10: very strong activity, <50: strong activity, <100: moderate activity, } \\
*LC = Lethal concentration (at 95 \% C.L), **S.E. = Standard error, \\
N.A. = Not available & &
\end{tabular}

LARVICIDAL ACTIVITY OF PURE COMPOUNDS

FROM Murraya koenigii AGAINST MOSQUITO LARVAE OF Aedes aegypti

\begin{tabular}{lcc}
\hline Pure compounds & $\mathrm{LC}_{50}(\mu \mathrm{g} / \mathrm{mL})^{*}$ & Slope \pm S.E** \\
\hline Mahanimbine (1) & 0.68 & $1.17 \pm 0.16$ \\
Girinimbine (2) & 0.79 & $1.07 \pm 0.14$ \\
Murrayacine (3) & 2.51 & $1.92 \pm 0.18$ \\
Murrayanine (4) & 1.14 & $1.08 \pm 0.16$ \\
Murrayafoline A (5) & 0.43 & $1.01 \pm 0.23$ \\
\hline$<10:$ very strong activity, < 50: strong activity, < 100: moderate \\
activity, *LC = Lethal concentration (at 95 \% C.L), **S.E. = Standard \\
error, N.A. = Not available
\end{tabular}

\section{ACKNOWLEDGEMENTS}

The authors thank School of Graduate Studies, Universiti Putra Malaysia for the Graduate Research Fellowship and Department of Chemistry, Faculty of Science, Universiti Putra Malaysia for the facilities provided.

\section{REFERENCES}

1. WHO, Geneva: World Health Organization (WHO) (VMONBC/81.807) (1981).

2. R. Borah, M.C. Kalita, A. Kar and A.K. Talukdar, Afr. J. Biotechnol., 9, 2527 (2010).

3. M.A. Sukari, N.Y. Rashid, B.K. Neoh, N.H. Abu Bakar, S. Riyanto and G.C.L. Ee, Asian J. Chem., 22, 7915 (2010).

4. Dietrich Brandis, Forestry in India, Dehra Dun, India (1971).

5. D.P. Chakraborty, S.P. Bhattacharya and A.K. Biswas, Phytochemistry, 17, 834 (1978).

6. Y. Tachibana, H. Kukizaki, N.H. Lajis and N. Nakatani, J. Agric. Food Chem., 49, 5589 (2001).

7. K. Nakahara, G. Trakoontivakorn, N.S. Alzoreky, H. Ono, M. OnishiKameyama and M. Yoshida, J. Agric. Food Chem., 50, 4796 (2002).

8. N.H. Abu Bakar, M.A. Sukari, G.C.L. Ee, M. Rahmani, A.M. Sharif, K. Khalid and U.K.Yusof, Malaysian J. Anal. Sci., 11, 173 (2007).

9. H. Furukawa, T.S. Wu, T. Ohta and C.S. Kuoh, Chem. Pharm. Bull., 33, 4132-4138

10. C.P.W. Zebitz, Proceeding of the 3rd International Neem Conferences, Nairobi, p. 555 (1986). 